\title{
DINÂMICA CULTURAL E CONSTRUÇÃO IDENTITÁRIA: REFLEXÕES EM TORNO DE UMA ETNOGRAFIA CONTEM PORÂNEA
}

Marcos Luciano Lopes Messeder ${ }^{1}$

Resumo: Este texto tem como proposta produzir uma reflexão metaetnográfica no contexto das relações interétnicas no Nordeste do Brasil, buscando descrever os caminhos teóricos e metodológicos que traçamos em nossa pesquisa sobre a relação entre o consumo de álcool e a etnicidade entre os Tremembé do Ceará. Em um primeiro momento, procuramos descrever o campo empírico da pesquisa, associando-o ao contexto das relações interétnicas que organizam a realidade dos índios no Nordeste. Em seguida, discutimos as tensões colocadas à elaboração do quadro teórico e metodológico a partir do qual construímos o trabalho de investigação. Ao final, apresentamos algumas reflexões sobre o conjunto dos dados recolhidos e suas implicações para a articulação entre política e elaboração cultural no âmbito dos estudos sobre etnicidade entre os índios no Nordeste brasileiro.

Palavras-Chave: Etnografia, Etnicidade, Dinâmica cultural.

Abstract: This article aims to produce an meta-ethnographic reflection in the context of interethnic relations in Northeastern Brazil, seeking to describe the theoretical and methodological itinerary followed during our research on the relationship between alcohol consumption and ethnicity among the Tremembé of Ceará. First, we describe the actual empirical field in which the research was carried out, referring it to the context of interethnic relations that organize the reality of the Indians in the Northeast. Then, we discuss the existing tensions as we elaborated the theoretical and methodological framework from which we construct the research work. Finally, we present some reflections on the set of data collected and its implications for the relationship between political and cultural development within the framework of studies on ethnicity among the Indians in the Brazilian Northeast.

Keywords: Ethnography, Ethnicity, Cultural Dynamics.

\section{INTRODUÇÃO}

Nosso propósito neste texto é produzir algumas reflexões sobre 0 processo de construção etnográfica no contexto das relações interétnicas no Nordeste do Brasil. De fato, trata-se de uma reflexão meta-etnográfica,

1 Doutor em Sociologia e Antropologia (Université Lumière Lyon 2); Professor Adjunto da Universidade do Estado da Bahia (UNEB); pesquisador associado do Centro de Estudos e Terapia do Abuso de Drogas da Universidade Federal da Bahia e do Programa de Pesquisa sobre Povos Indígenas no Nordeste (PINEB/UFBA); membro da diretoria da Associação Nacional de Ação Indigenista (ANAÍ-BA). Endereço eletrônico: marmesseder@terra. com.br. 
posto que procuramos descrever os caminhos que traçamos na pesquisa e como combinamos certas referências teóricas com um conjunto de procedimentos metodológicos típicos do trabalho antropológico para dar conta de um objeto recortado por dois eixos de problematização, a saber: a etnicidade, entendida como elaboração política e o consumo de bebidas alcoólicas, enfocando particularmente as práticas rituais de uma bebida tradicional, mas também situações dramáticas de uso problemático nos quais se evidenciam dilemas existenciais e identitários.

Em um primeiro momento, procuramos descrever o campo empírico da pesquisa, associando-o ao contexto das relações interétnicas que organizam a realidade dos índios no Nordeste. Em seguida, discutimos o horizonte teórico e metodológico a partir do qual construímos o trabalho de investigação. Ao final, apresentamos algumas reflexões sobre o conjunto dos dados recolhidos e suas implicações para o entendimento do nosso objeto de estudo. Nossa intenção é contribuir com os esforços feitos em nossa disciplina para uma reflexão contínua sobre o processo de construção etnográfica.

\section{BREVE CONTEXTUALIZAÇÃO: ÍNDIOS, RITUAIS, RELIGIÃO E CONSUMO DE ÁLCOOL}

Os índios no Nordeste do Brasil integram um conjunto de populações marcadas por séculos de contato com a sociedade colonial e nacional, do qual resultou uma situação de fraca distinção cultural e um trabalho intenso de reelaboração simbólica em torno do passado e das tradições. Nossa pesquisa ${ }^{2}$ interrogou uma realidade onde uma população historicamente estigmatizada e folclorizada se encontra, depois de algumas décadas, em pleno processo de reconstrução política e cultural. Ao centro deste processo se coloca um ritual de consumo de uma bebida fermentada tradicional, chamada mocororó ou garrote ${ }^{3}$, feita a partir do suco do caju. Alguns fragmentos simbólicos encontrados em sessões locais de Umbanda quando do nosso primeiro trabalho de campo entre os Tremembé, na década de 1990,

2 Para o desenvolvimento deste trabalho contamos com uma bolsa de doutorado pleno no exterior da Coordenação de Aperfeiçoamento de Pessoal de Ensino Superior (CAPES), no período compreendido entre os anos de 2000 a 2004.

3 No quarto capítulo de nossa tese (MESSEDER, 2004) há uma etnografia detalhada das formas de preparação do mocororó e uma discussão sobre os significados das suas denominações.

70 Número temático: M etodologias de pesquisa em ciências sociais e humanas. A Cor das Letras - UEFS, n. 14, 2013 
colocaram-nos na pista do lugar do índio e da bebida naquele contexto. $\mathrm{Na}$ Umbanda existe um conjunto bastante vasto de entidades espirituais, representando o universo africano, indígena e mestiço do Brasil. Os índios são enquadrados na categoria caboclos, o que indica de início seu caráter racialmente mestiço, o que não é sem ambiguidade. Um fato interessante é que estas entidades são percebidas como bebedoras e se incorporam, às vezes já embriagadas ${ }^{4}$.

Tal fato conduziu-nos a procurar uma articulação entre o imaginário religioso, as práticas rituais de alcoolização entre os índios e os processos de construção identitária. Ademais, o ritual Tremembé, o Torém, sempre foi percebido, como veremos adiante, por folcloristas e antropólogos, como um ritual lúdico, muito embora nas pesquisas antropológicas contemporâneas a ênfase tenha recaído na sua função política de demarcador de fronteira étnica. Outras populações indígenas do Nordeste, enfrentando as mesmas questões de afirmação e legitimidade cultural, têm em seus rituais religiosos uma fonte fundamental de elaboração simbólica. Era evidente para nós, em função dos contatos com essas populações e por outras razões, que os Tremembé tenderiam a sacralizar seu ritual. Nossa hipótese foi confirmada em campo. Ao lado disso existe a alcoolização cotidiana ligada às atividades profissionais, particularmente à pesca, mas também a agricultura. Nós partimos à procura das significações do beber e das bebidas, articulando todas essas dimensões: étnica, social, existencial e religiosa. A ideia de base é que todas estas práticas e crenças fazem parte de um exercício de composição de si, tanto no plano coletivo como subjetivo.

A população que nós estudamos habita a costa noroeste do Estado do Ceará. Os Tremembé são reconhecidos oficialmente como população indígena pelo Estado brasileiro e têm um território identificado, mas não ainda demarcado, tendo em vista contestações de ocupantes. Todo conflito está aí, no reconhecimento social e cultural da existência atual dos Tremembé. Um quadro ambíguo e tenso organiza a vida social e política local. Nós o conhecemos há vinte anos atrás e a situação atual revela as mudanças e as permanências. Esta população vive espalhada por várias localidades

4 Em duas das sessões que presenciamos no referido período, um mesmo caboclo fechou os cultos incorporando-se já bêbado. Na época acreditamos tratar-se de uma entidade indígena, mas soubemos que era uma espécie de caboclo "genérico", sem especificação étnica. De qualquer sorte, naquele momento, a evocação daquela entidade parecia configurar a materialidade do estereótipo do índio bêbado e ao mesmo tempo espiritualmente lúcido. 
do município de Itarema, situado à cerca de $260 \mathrm{~km}$ da capital do Estado, Fortaleza. Uma parte considerável das famílias identificadas como sendo Tremembé habita não muito distante do distrito de Almofala e seus entornos. Almofala, diga-se de passagem, é onde se situa a igreja construída no século XVIII como marco da missão religiosa que catequizou os Tremembé. A dispersão e fragmentação atual resultam de um longo processo histórico feito de oscilações e ambiguidades.

Neste contexto, marginalidade e alteridade são componentes fundamentais da trama de consumo. Quais são as assimilações simbólicas possíveis das experiências de alcoolização neste quadro? Véronique NahoumGrappe (1991) nos ensina que a alteração na percepção de si reorientaria um investimento da presença no mundo e novos sentidos podem ser propostos para experiências culturais conhecidas. Desta forma um ritual de alcoolização coletiva, em um contexto de forte discriminação, pode se tornar uma rica fonte de ressignificação da experiência étnica e da reflexividade (TURNER, 1985) que acompanha estes dramas. Para começar, examinemos a estrutura básica do ritual Tremembé e sua relação com formas análogas de outros povos indígenas no Nordeste.

0 Torém é um ritual muito simples na sua estrutura, compreendendo uma dança circular acompanhada de cantos, que, em princípio, fazem referência à fauna e à flora locais. Ao centro do círculo de dançadores está 0 condutor do ritual, portando um maracá na mão para marcar o ritmo dos cantos que ele mesmo entoa. A dança segue o sentido anti-horário, salvo durante a execução de um canto específico que fazem os dançarinos rodarem na direção contrária, somente o tempo de um verso. Existe uma pausa para beber o mocororó, geralmente após seis canções, indicada por uma canção particular.

Na região Nordeste, os grupos indígenas têm rituais muito próximos desta estrutura, o mais conhecido se chama Toré e é praticado pela maior parte das populações indígenas da região. É preciso de qualquer maneira atentar para as diferenças existentes entre Torém e Toré, no que concerne aos cantos, aos passos da dança, ao tipo de bebida utilizada, ao significado destas bebidas e à possessão por espíritos. 0 Toré é classificado como lúdi-

5 Para uma análise da importância histórica e memorial da igreja na conformação da etnicidade Tremembé, sugerimos a consulta aos trabalhos de Carlos Guilherme 0. do Valle, (1993) e Marcos Luciano L. Messeder (1995), além da nossa própria tese (Messeder, 2004).

72 Número temático: M etodologias de pesquisa em ciências sociais e humanas. A Cor das Letras - UEFS, n. 14, 2013 
co e sagrado, dependendo do contexto de sua realização. Aqueles que executam o Toré dizem que ele pode ser uma diversão, se ele é apresentado fora da aldeia, mas que ele é uma cerimônia sagrada, durante a qual ocorre a incorporação e a consulta dos espíritos, o consumo de uma bebida ritual e do tabaco, no quadro das realizações internas aos grupos indígenas.

Nós poderemos encontrar estes mesmos elementos em cultos de possessão, que podem se nomear torés, praticados por populações mestiças sem nenhuma reivindicação étnica e, particularmente, poderemos observar devoções no seio de religiões constituídas, como a Umbanda e 0 Candomblé, a entidades denominadas caboclo, onde o tabaco e as bebidas alcoólicas são fortemente notadas ${ }^{6}$. Uma planta chamada Jurema ${ }^{7}$ (mimosa bentis ou hostilis) é um componente associado de maneira particular aos índios em todos os rituais deste tipo no Nordeste do Brasil. A Jurema é ao mesmo tempo uma planta, uma entidade, a bebida feita da entrecasca de sua raiz e um reino onde se crê que habitam os mestres espirituais, às vezes, nomeados encantados, sendo todos tidos como índios.

Este "universo do sagrado indígena", se nós ousamos lhe nomear assim, releva de um trabalho de recomposição das significações de vários elementos presentes no imaginário a propósito do índio e nas práticas e crenças incorporadas à experiência religiosa das populações indígenas e mestiças do meio rural nordestino. No plano imaginário da Umbanda e do Candomblé, o índio é associado à natureza, o que não é sem relação com as representações (interpretações) construídas pela literatura romântica que impregnou o processo ideológico de construção da nação brasileira. Paralelamente, nesta mesma época, fim do século XIX, as populações indígenas estavam sendo desconstruídas física e ideologicamente, particularmente no Nordeste, onde começou, lembremos, a colonização do país. Os índios tornam-se espíritos ou traços do caráter incorporados seja nos cultos marginais dos escravos e mestiços, seja como virtudes abstratas do povo brasileiro: valente, forte, corajoso. Concretamente, as populações indígenas do Nordeste passam o fim do século XIX e o começo do século XX quase esquecidas e mesmo dadas como desaparecidas para sempre.

6 A propósito do lugar dos índios no Candomblé da Bahia sugerimos consultar o trabalho de Jocélio T. dos Santos (1995).

7

Nós remetemos ao terceiro capítulo de nossa tese onde analisamos a religiosidade e os rituais dos índios do Nordeste. A Jurema aparece em vários registros simbólicos. Nesta parte, nós utilizamos como fonte o trabalho de M arco T. S. Nascimento (1994) que discute especificamente a existência do que ele denomina de "complexo ritual da Jurema". 
O Torém Tremembé foi visto ao longo do século XX como uma relíquia folclórica de um passado indígena sem retorno (Florival Seraine, 1955). Nos últimos anos, o ritual tornou-se um elemento chave no processo de distinção étnica dos Tremembé e foi apreendido como signo diacrítico na construção da organização política do grupo (Carlos G. O. do Valle, 1993; M arcos M esseder, 1995 e Gerson de Oliveira Junior, 1998). M esmo o último trabalho, que trata exclusivamente do ritual, enfatiza sua função política e integrativa e tem por título Torém: Brincadeira dos Indios Velhos (Gerson de Oliveira Junior, 1998), o que acentua o caráter lúdico e remetido ao passado.

Aqui cabe uma pequena digressão sobre um encontro com um fotógrafo que trabalhou entre os Tremembé nos anos 1970. Quando estávamos em campo (2002) na véspera do último ritual a que assistimos, em pleno ano novo, tivemos notícia de sua presença na área. Estávamos hospedados na casa do cacique e conversávamos com ele, contando piadas, quando chegou o fotógrafo e o cacique nos apresentou. Depois das trocas de cumprimentos e algumas falas banais, nós começamos uma discussão bastante árdua sobre as mudanças do Torém. Ele dizia lamentar as tendências atuais de incorporação de outros cantos, em português notadamente, salientando que a "tradição" era aquela descrita por Florival Seraine. De nossa parte, tentamos salvaguardar o direito dos produtores culturais de dar a direção que thes parece a mais correta.

0 episódio guarda certo lado irônico pelo fato da discussão ter tido lugar na presença do cacique, que contemplava a cena estirado sobre uma rede. Tal situação ilustra perfeitamente a importância das intensas atividades de pesquisa em Almofala desde os anos de 1950, exatamente com a vinda de Florival Seraine. 0 encontro explicita os embates dialógicos e ideológicos aos quais são confrontados os Tremembé. Missionários, pesquisadores de todos os tipos, militantes de ONG, jornalistas se cruzam e trocam seus pontos de vista em diálogo com os índios, os quais se apropriam a sua maneira destes discursos para compor sua própria imagem.

\section{O HORIZONTE TEÓRICO-METODOLÓGICO: OS EIXOS DA PESQUISA E SUA ARTICULAÇÃO}

A antropologia se instituiu como disciplina buscando dar conta da diversidade na unidade ou vice-versa. Sua perspectiva inicial assegurou a unidade através da montagem de uma história linear, assimilando o dife-

74 Número temático: M etodologias de pesquisa em ciências sociais e humanas. A Cor das Letras 
rente ao passado. Devemos compreender esta visão no quadro positivista e evolucionista característico do século XIX. A dinâmica do conhecimento antropológico se associa, de um lado, às mudanças epistemológicas engendradas pelo desenvolvimento do trabalho de campo e, de outro, pelo movimento de transformações sociais, políticas e culturais forjadas pela própria história da humanidade. Passa-se, então, de um conceito do primitivo quase privado de razão para uma perspectiva segundo a qual estes outros, as sociedades não ocidentais, se fundam sobre lógicas culturais específicas e inteligíveis à luz de um olhar de "dentro". Bronislaw Malinowski (1978), com sua análise de um ritual de troca melanésio, foi o pai fundador de uma tradição etnográfica marcada pela experiência da observação participante, este paradoxo da disciplina, que Vicent Crapanzano (1991, p. 60) não hesita em qualificar de oxímoro "da especificidade metodológica da antropologi$a^{\prime \prime}$.

Nossa trajetória na disciplina se inicia com o estudo de grupos indígenas do Nordeste. Estes índios constituem o contra senso de uma visão fixa da cultura. A questão que se coloca inicialmente para análise da sua continuidade no tempo, enquanto entidades étnicas discretas, é justamente o caráter residual da cultura (CUNHA, 1986) que Ihes serve de base. Após quatro séculos de contato intensivos com a sociedade colonial e nacional, constrangidos a assimilar, no quadro das missões católicas, uma religião e um modo de vida, em uma palavra, uma cultura, obrigados a constituir uma unidade na diversidade das etnias reunidas nas missões, eles chegam à modernidade despossuídos dos signos exteriores de suas particularidades culturais. Sem suas línguas (com uma só exceção), reivindicando seus territórios, renomeados "caboclos", como resultado semântico de uma indistinção cultural e mais ainda como marca discriminatória desta indistinção, eles eram, nos termos teóricos do culturalismo ${ }^{9}$, "aculturados". Logo, estamos

8 Veremos mais adiante em que contexto o autor produz esta crítica. Mas podemos adiantar que Crapanzano realça obviamente a situação ambígua da observação participante como uma interação social na qual o sujeito se distancia para ver melhor e se implica para entender a experiência de fazer parte de um grupo. Temos aí, portanto, o paradoxo posto que observar é extrair-se da relação e participar é imergir no fluxo desta mesma relação.

9 O culturalismo pode ser sumariamente definido como uma perspectiva teórica produzida nos EUA que toma as culturas como conjunto de traços integrados, definindo uma configuração específica e substantiva. Estas ideias prevaleceram até meados da década de 1950 quando começaram a ser criticadas. Deram origem a conceitos correlatos como de aculturação, supondo que 0 contato cultural entre sociedades fortemente desiguais de- 
em face de uma situação etnográfica muito distante do parâmetro corrente da antropologia clássica. Esta última se atribuía a tarefa de comparar sociedades em um quadro de estabilidade cultural para chegar à elaboração de leis gerais da evolução histórica e mais tarde, propondo os esquemas funcionais da vida em sociedade (M ALINOWSKI, 1978) ou os modelos do pensamento humano (cf. LÉVI-STRAUSS, 1976), todos obviamente universalisantes.

Nós encontramos o sujeito de nossas pesquisas nos anos de $1990 \mathrm{em}$ outro contexto histórico e epistemológico da disciplina. Trata-se de exorcizar os fantasmas do evolucionismo e do culturalismo, senão ainda vivos, pelo menos assombrando por aí, para compreender a reconstituição de grupos dados como desaparecidos ou mesmo a reavivação de projetos particularistas no meio de um mundo modernizado e tendendo à homogeneidade cultural. Este mundo é aquele da descolonização e da penetração do discurso antropológico, visto como apologia da diferença, esta produto de um processo complexo de construção social. Aqui as articulações entre a produção de discursos científicos e as apropriações ideológicas tornam-se mais evidentes, como é o caso dos trabalhos sobre gênero e as elaborações feministas dos anos cinquenta do século XX.

Novas narrativas não surgem do campo de pesquisas antropológico, como as vezes contamos aos nossos estudantes de graduação, mas da história, de condições mundiais. A história da aculturação indígena foi parte do sonho americano, a expansão da fronteira, a conquista das terras selvagens, e da americanização dos imigrantes. Após a Segunda Guerra Mundial o mundo mudou, com a derrota do colonialismo, a emergência de novos estados, 0 movimento de direitos humanos, e uma nova concepção de igualdade. Estruturas narrativas mudaram em conformidade (BRUNER, 1986, p. 151-2).

Antes, esta relação ficava frequentemente na sombra, o evolucionismo como legitimação da política colonial europeia é a demonstração mais explícita ${ }^{10}$. Nós entramos aí definitivamente na fase dos conflitos, das

sencadeava, necessariamente, a perda da cultura da sociedade mais vulnerável. 0 culturalismo propunha então que o processo de modernização atingindo as chamadas sociedades tradicionais levaria a sua assimilação inevitável. Sabemos que isto não ocorreu e de certa forma os processos de homogeneização conduziram a uma onda de particularismos.

10 Ver Frantz Fanon (1968), como o exercício o mais radical de desmascaramento ideológico e como afirmação invertida de contra história.

76 Número temático: M etodologias de pesquisa em ciências sociais e humanas. A Cor das Letras 
mudanças, das tensões e da afirmação do cultural como esfera política (MONTERO, 1991, p. 119).

Ora, fazer pesquisa sobre índios do Nordeste, nesta época, implicava a utilização de um arsenal teórico e metodológico forjado pela antropologia política. Foi a partir dos trabalhos de Georges Balandier (1951), na França e de Max Gluckman (1987), na Inglaterra, entre outros, que puderam ser elaboradas novas abordagens, incorporando a mudança na análise das relações interétnicas. Roberto Cardoso de Oliveira $(1964,1976,1978)$ foi um dos pioneiros, no Brasil, na elaboração de uma perspectiva dinâmica das relações interétnicas. Como pesquisador situado em um espaço periférico da produção intelectual mundial (PEIRANO, 1991) suas fontes foram os trabalhos citados acima e o de Frederik Barth (1968) e sua famosa introdução aos problemas de constituição das fronteiras dos grupos étnicos.

Os índios do Nordeste foram apreendidos por diversas pesquisas a partir de um olhar politizante da cultura. Nossa experiência de pesquisa com os Tremembé, no começo dos anos de 1990, terminou plena de lamentações por ter privilegiado as relações de poder e sua análise sociológica em detrimento de uma abordagem mais simbólica. A pesquisa que elaboramos emerge de um desejo de compreensão de planos ocultados pelas abordagens sociológicas e políticas já referidas de um universo rico em tensões e ambiguidades de toda ordem.

A problemática centra-se sobre dois eixos de análise que precisavam ser combinados da maneira mais dinâmica possível. De um lado, deveríamos analisar a constituição do movimento histórico de reivindicação étnica Tremembé. De outro, tratava-se de penetrar o coração das práticas de alcoolização na busca dos sentidos elaborados pelos sujeitos e sua relação com a identidade étnica. Sumariamente, a intenção é entender o sentido da composição de si, ato ao mesmo tempo individual e coletivo, através de uma experiência etnográfica centrada sobre as oscilações e tensões identitárias propiciadas pelos atos rituais e dramáticos da alcoolização. Compreende-se assim que nosso propósito visava abrir possibilidades interpretativas de um objeto que recobre simultaneamente componentes objetivos, investigáveis através da configuração histórica e social do movimento político de construção da identidade étnica e outras dimensões situadas na encruzilhada das relações intersubjetivas entre ordem e desordem, autêntico e simulado, estigmatização e reconhecimento social. Os modelos rígidos, postulando uma ideia de ordem estruturada e não modulares, seriam pouco apropriados para dar conta de tal situação etnográfica. A análise de al- 
gumas tendências atuais na antropologia ofereceu orientações pertinentes ao nosso caso.

Roberto Cardoso de Oliveira (1995), em um ensaio instigante intitulado "A categoria de (des)ordem e a pós-modernidade da antropologia", propõe que a noção de ordem orienta a gramaticalidade da linguagem antropológica. Ele identifica os paradigmas vinculados a esta noção, a saber: 0 racionalista, o estrutural funcionalista e o culturalista, respectivamente ligados às principais escolas do pensamento antropológico, a francesa, a inglesa e a norte-americana.

[...] o paradigma racionalista, já nos seus primeiros passos na École française, aplica-se tanto à questão da organização social (solidariedade mecânica e solidariedade orgânica) como na descoberta de "formas elementares" ordenadoras do pensamento primitivo, e, em seus últimos passos, no exercício radical da categoria, já no interior do moderno estruturalismo francês, como bem ilustra a conhecida máxima lévi-strausseana de que "a pior ordem é meIhor do que a desordem"; na questão equacionada em termos de estrutura social, destaca-se o paradigma estrutural-funcionalista particularmente no que diz respeito à instituição do parentesco e aos grupos organizacionais tão extensamente estudados na British School; enquanto que o paradigma culturalista, subjacente a American Historical School of Anthropology, conduz a indagação para os processos culturais e ao estabelecimento de padrões os regularidades culturais (OLVEIRA, 1995, p. 17).

Desta forma, a desordem, as tensões, as mudanças e as contradições ficavam como o impensado da disciplina ou mais precisamente eram submetidos a uma domesticação. Todos estes elementos se associam em parte ao tempo e à história, mas há ainda outros considerados como irracionais, a exemplo da emoção, dos afetos, os sentimentos forjados na intersubjetividade.

Bela Feldman-Bianco (1987) analisa, por seu turno, as transformações metodológicas que conduziram a antropologia britânica a repensar a ação. A este propósito a virada se realiza após a II Guerra onde a questão passa de "como a sociedade se mantém" a "como a sociedade se transforma". Os progressos foram consideráveis e chegou-se a noções mais flexíveis como "campo" no lugar de sistema, para pensar as interações e seus movimentos, colocando a ênfase sobre as relações tensas e conflitivas entre os agentes sociais, o que supôs, paralelamente, recolocar os agentes na cena, não como meros elementos de sistemas impessoais e objetivados. Neste sentido, Max Gluckman (1987) e Van Velsen (1987) propuseram a análise de situações sociais para dar conta dos fluxos interativos, associado ao o-

78 Número temático: M etodologias de pesquisa em ciências sociais e humanas. A Cor das Letras 
Ihar microscópico voltado para os conflitos, as tensões, e, sobretudo, a ação social. Estas noções serviram para balizar a construção de modelos mais adaptados à investigação de contextos sociais complexos onde vários agentes, com posições, interesses e valores diferentes estão interagindo. No que se refere às relações interétnicas, no Brasil João Pacheco de Oliveira Filho (1988) elaborou noções como "situação histórica", "territorialização" e outras mais instrumentais, a exemplo de "campo intersocietário", dialogando com as proposições citadas acima e aquelas de Georges Balandier.

Vemos que uma das dimensões da nossa problemática se articula claramente com essas perspectivas. Entretanto, fica ainda fora do campo desta visão a questão da cultura como organizadora da ação e todo o processo de reelaboração simbólica que acompanha as mudanças sociais. Lembremos que é da fonte sociológica da antropologia, aquela forjada por Radcliffe-Brown e seus discípulos, que vem a inspiração destas transformaç̧ões. É do movimento hermenêutico, como Ihe designa Roberto Cardoso de Oliveira (1995), que tem em Clifford Geertz sua referência fundamental, de onde vêm as contribuições centrais para um pensamento da dinâmica cultural.

0 quarto paradigma de nossa matriz disciplinar, que chamei de hermenêutico, abre seu espaço na antropologia primeiramente por uma negação radical daquele discurso cientificista exercitado pelos três outros paradigmas; em segundo lugar, por uma reformulação daqueles três primeiros elementos que haviam sido domesticados pelos paradigmas da ordem: a subjetividade que, liberada da coerção da objetividade, toma sua forma socializada, assumindose como inter-subjetividade, 0 indivíduo, igualmente liberado das tentações do psicologismo, toma sua forma personalizada (portanto o indivíduo socializado) e não teme assumir sua individualidade; e a história, desvencilhada das peias naturalistas que a tornavam totalmente exterior ao sujeito cognoscente, pois dela se esperava fosse objetiva, toma sua forma interiorizada e se assume como historicidade (OLIVEIRA, 1995, p. 25).

Este movimento permite incorporar ao discurso antropológico a alteridade como parte integrante da construção etnográfica. No lugar de excluir as hesitações, as tensões e as contradições da ordem cultural e da ação social, ele procura Ihes fazer falar. Paul Rabinow se refere à emergência deste movimento como resultado da "crise de representação na escritura etnográfica" (RABINOW, 1986, p. 251 apud OLVEIRA, 1995, p. 32). As relações dialógicas propostas engendram um saber negociado onde o pesquisador e os sujeitos da pesquisa fazem interagir seus horizontes, segundo a terminologia empregada pelos hermeneutas. A ideia de um autor soberano não existe nesta perspectiva onde o encontro é também possibilidade de 
confrontação. 0 etnógrafo não é o único intérprete dos dados, devendo integrar o saber do outro. Trata-se de abrir uma via para a polifonia.

Um dos mais ardentes defensores desta nova ótica da antropologia é Georges M arcus (1991). Do seu ponto de vista, as identidades são determinadas de várias formas na modernidade, exigindo novas estratégias etnográficas. Ele critica de início as perspectivas sobre o tema que privilegiam as noções de resistência e acomodação, pois de qualquer maneira estas categorias implicam uma estrutura cultural estável, em detrimento de uma visão incluindo contradições duráveis. As etnografias ligadas a estas noções tentam evitar o sentido paradoxal da imbricação entre a diversidade e a homogeneidade.

Estou especialmente interessado em analisar como se cria um texto modernista em cada trabalho que tenta mostrar de que modo identidades específicas se criam a partir de turbulências, fragmentos, referências interculturais e a intensificação localizada das possibilidades e associações globais (M ARCUS, 1991, p. 204).

Para atingir estes objetivos, 0 autor sugere alguns pré-requisitos etnográficos, cujas implicações epistemológicas são evidentes. Em primeiro lugar, deve-se redefinir o observado, problematizando de entrada o conceito de comunidade, muito espacializado, posto que é preciso analisar múltiplos contextos onde as identidades são por vezes dispersas e fragmentadas. A historização da etnografia torna-se indispensável, a memória tomada de forma individualizada proporcionaria uma melhor avaliação das experiências históricas. Isto refunda as representações coletivas, a partir do vivido e provoca a incorporação de várias vozes. Ele mantém a necessidade do conceito de estrutura social, mas o desloca em termos de determinação das experiências, estas últimas expressas na polifonia, constituindo a estrutura em um plano sentimental.

Paralelamente, 0 observador deve refazer-se na sua prática. A maior parte do tempo, o que ele chama de "etnografias realistas" se construíram a partir de uma exegese dos símbolos e das concepções indígenas extraídos dos seus contextos e reinterpretados de acordo com as exigências do esquema analítico do etnógrafo. Ele fala de um necessário exercício dialógico cuja exegese se baseia sobre a etnografia e a estrutura analítica, de modo a explicitar, ao menos, duas vozes, recriando assim os conceitos no seio do discurso teórico. A questão para ele é saber "[...] se uma identidade pode ser explicada a partir de um só discurso de referência, quando de fato vários discursos entram em cena [...]" (Id., p. 211). Haveria uma multilocaliza80 Número temático: M etodologias de pesquisa em ciências sociais e humanas. A Cor das Letras 
ção dos processos identitários cruzando vários níveis transculturais e estabelecendo ligações de valor e de razões pessoais entre o etnógrafo e seu objeto.

As proposições de Georges M arcus e outros autores podem ser confrontadas com o problema das relações de poder engendradas pelo exercício mesmo da etnografia, além daqueles já explicitados pelas relações entre grupos e sociedades. Ele coloca desta maneira a necessidade de uma ética capaz de abrir uma via de acesso ao reposicionamento do outro na história da humanidade. 0 dilema se funda na tensão forjada pela trama histórica da experiência etnográfica e sua tradução nos quadros de objetividade prescritos a este tipo de exercício intelectual. A historicidade é múltipla, mas existe uma maneira bem ordenada de contá-la e, então, tudo parece entrar em ordem, mesmo quando as contradições se apresentam.

As angústias colocadas por estas proposições críticas se associam àquelas já presentes na prática das ciências humanas de uma maneira geral como nos ensina Georges Devereux (1980). As disposições dialógicas propostas por uma parte dos antropólogos contemporâneos (ver particularmente Dennis Tedlock [1979]), apresentam certas ingenuidades se não as tomarmos de forma crítica. Vicent Crapanzano (1991), em um texto que se chama simplesmente "Diálogo", realiza uma discussão bastante crítica, dizendo de início que esta palavra parece ter substituído a observação participante. Esta última, como vimos, é designada por ele de oxímoro. 0 diálogo sugere o romantismo ligado ao pólo participante.

[...] ocultando a angústia associada ao pólo observante, angústia ligada ao efeito de distância da observação. Ela sugere amizade, mutualidade, autenticidade, em uma relação igualitária. Assim entendida, diálogo não somente descreve tais relações, como pode criar a ilusão de que elas efetivamente existem. Eu não me refiro aqui, continua o autor, a má fé, que pode, evidentemente, existir, mas a possibilidade de uma cegueira inerente à situação (dialógica) na qual se encontra 0 antropólogo. Logo, o diálogo não somente revela, como ele pode frequentemente ocultar as relações de poder e os desejos que estão por trás da palavra falada e, em outros contextos, da palavra escrita e divulgada. 0 poder e 0 desejo podem contradizer a amizade que 0 diálogo conota (CRAPANZANO, 1991, p. 60).

0 autor está preocupado com uma precisão no uso do dispositivo dialógico. Neste sentido, ele incita a distinguir o sentido metafórico do diálogo e o diálogo propriamente dito. É o caso, por exemplo, do uso do diálogo para se referir à discussão intertextual que nós fazemos quando escrevemos nossas etnografias. Atenta também para o fato de que a prática 
interpretativa da etnografia recompõe os sentidos e não simplesmente os restitui por escrito.

Ao examinar a etimologia da palavra, o autor reafirma os princípios críticos que acompanham o seu exercício. Diálogo origina-se do grego, associando a preposição "dia", que significa "por meio de", "entre", "através" e "logos", derivado de legein, falar, ou podendo também designar materialmente "sopro", "espírito", segundo a interpretação proposta por Onians (apud CRAPANZANO, 1991, p. 66). Então, “[...] diálogo é um falar através, entre e por intermédio de duas pessoas. Ele é uma passagem e um distanciamento. Um diálogo tem tanto uma dimensão de transformação quanto de oposição, agonística. É uma relação altamente tensa" (Id., p. 66).

Vários momentos no trabalho de campo evidenciaram estas dificuldades. Em pelo menos três ocasiões de entrevista deparamo-nos com situações delicadas na construção do diálogo, descreveremos apenas duas das mais emblemáticas. Em um primeiro caso, entrevistávamos uma jovem com uma história de alcoolização pesada e com experiências fortemente marginais de convivência com bandidos e participação em brigas e atos de violência, além de uma vida conjugal e familiar conflituosa. Em determinado momento da sua narrativa, a carga emocional era tamanha que silenciamos para respeitar seu choro. A sensação de que ali se desenrolava uma espécie de catarse nos fazia também refletir sobre os limites do exercício da investigação, em que pese ao final termos avaliado, em conjunto com nossa entrevistada, que a conversa havia sido reciprocamente proveitosa.

Em outro episódio, fomos convidados por um personagem estratégico da vida local, um índio que passou a se negar enquanto tal, para uma entrevista em um bar, quando ele se encontrava bêbado. A entrevista era 0 sonho da pesquisa, todos os elementos das tensões e contradições reunidos em um só lugar e em uma só pessoa. Contudo, se colocava o dilema ético do oportunismo da pesquisa em condições de vulnerabilidade do outro. 0 desafio foi aceito e procuramos na apresentação dos dados desta entrevista examinar também estas contradições que nos atravessavam, discutindo também o estatuto da vontade e da verdade de sujeitos em estados alterados de consciência. O óbvio do óbvio é que toda verdade é relativa e contextual, ademais no discurso sobre si mesmo e sua comunidade. Mais importante parece-nos fazer casar estes momentos com os nossos próprios princípios de entendimento da realidade social, vista não como ordem estruturada e sim como processo sempre dinâmico, reordenado pelas experiências concretas dos sujeitos em interação.

82 Número temático: M etodologias de pesquisa em ciências sociais e humanas. A Cor das Letras - UEFS, n. 14, 2013 
É preciso, portanto, levar em consideração as limitações inerentes ao exercício do diálogo etnográfico. Assumir e justificar as estratégias utilizadas em conformidade com os objetivos da pesquisa é o caminho honesto para uma postura ética. Todas as precauções tomadas para dar conta das situações de diálogo não anulam o imperativo do trabalho interpretativo do antropólogo. Não há saída para os dilemas colocados pela pesquisa além do enfrentamento das tensões e limites que ela engendra. Se a dialogicidade aparece como uma boa via para discussão do trabalho etnográfico, ela não deve ser idealizada como uma situação plena de simetria e igualdade.

\section{SENTIDOS E REFLEXÕES DA ELABORAÇÃO ETNOGRÁFICA: A AMBIGUIDADE DO ÁLCOOL E DA IDENTIDADE ÉTNICA}

Toda esta reflexão faz parte das inquietações geradas pelo nosso percurso de pesquisa. Tais inquietações se inscrevem no coração do nosso exercício antropológico e não as podemos elidir, considerando os engajamentos assumidos na pesquisa. Nossa investigação realiza uma conexão entre dimensões diferenciadas da realidade social, articulando uma visão das relações de poder, historicamente forjadas no seio da sociedade brasileira com práticas rituais e cotidianas de consumo de álcool.

A primeira dimensão foi pensada organizando uma leitura histórica das ações políticas dos agentes coloniais e nacionais definidoras do lugar dos índios tanto sobre o plano territorial quanto simbólico. Nossa intenção foi de refletir sobre uma realidade complexa de reivindicações identitárias atuais forjada por um processo bastante intrincado de assignação e destituição dos índios enquanto sujeitos. Procuramos mostrar como, ao longo desta história, que vai da colonização aos dias atuais, a oscilação quanto ao reconhecimento da diferença cultural foi um campo propício a vários tipos de manipulação e reificação.

Nós contamos esta história de uma maneira oblíqua, atravessando certos períodos, tomando um caminho aparentemente linear, mas com um passo hesitante, procurando uma interpretação entre os múltiplos sentidos propostos pelas narrativas orais e a historiografia formal. Não há uma discussão teórica sobre os estatutos diferenciados da história escrita e da memória oral, a questão não é estabelecer a legitimidade ou especificidade de cada um destes regimes discursivos, mas o sentido que eles têm para aqueles que os manipulam.

Para ser mais direto, passamos agora a uma descrição do conjunto de procedimentos teórico-metodológicos utilizados para construir a etnografia 
da etnicidade Tremembé, articulada com os processos de alcoolização. Em um primeiro momento, procuramos dar conta do processo através do qual os Tremembé são confinados em um dado território e dados como desaparecidos dois séculos depois, apesar do fato de haver um registro de terra coletivo relativo à Missão religiosa que os abrigou, datado do século XIX. Evidencia-se, desde logo, o problema crucial da terra, habitada e depois vista como "assombrada" pelos índios "fantasmagóricos" que deveriam ter desaparecido. Podemos então acompanhar a eficácia dos mecanismos ideológicos e políticos de assignação e de desaparecimento coletivo de uma população. A noção de "territorialização" (OLIVEIRA FILHO, 1988) ajuda-nos a abordar a questão.

Trata-se aqui de outro diálogo (no sentido metafórico), entre os diversos que compõem nosso trabalho, estabelecido com a antropologia brasileira de maneira a compreender meu olhar e dos meus colegas que trabaIham sobre a temática. Aproveitamos da distância proporcionada pelo fato de escrever em um país estrangeiro para experimentar com outra perspectiva a "esquizofrenia flutuante"11 que envolve a nossa disciplina, neste vai e vem entre 0 estranhamento e a proximidade que os nossos diários de campo cristalizam. Esta visão guiou a escritura da parte dedicada à discussão da noção de etnicidade, seus limites, perspectivas e aplicação pelos antropólogos que investigaram os Tremembé, eu mesmo aí incluído.

Em um segundo momento desta discussão inicial, ainda com o apoio das noções propostas por João Pacheco de Oliveira Filho (1988), procuramos entender as questões em torno da memória coletiva Tremembé e os esquemas de poder tecidos na relação com os regionais, entendidos aqui como comerciantes, fazendeiros e "coronéis". A memória da configuração da estrutura fundiária assume aí um papel central. Ela também é feita de oscilações presentes nos discursos que enunciam a dominação. Aqui e ali começamos a perceber alguns elementos a propósito dos estigmas étnicos e sua estabilidade ao longo da história local. Mas, sobretudo, aprendemos que 0 universo social e cultural no qual adentramos é pleno de ambiguidades.

${ }^{11}$ Faz-se necessário salientar a liberdade que me permito no uso dos pronomes que variam conforme o contexto da escritura etnográfica. A primeira pessoa do plural predomina em todo o texto, mas eu me coloco na primeira pessoa do singular a cada vez que o contexto incita a demarcação de um sentido mais pessoal. Esta oscilação está obviamente sujeita a caução, contudo ela funciona como uma fórmula textual para evidenciar a esquizofrenia flutuante que acabei de mencionar.

84 Número temático: M etodologias de pesquisa em ciências sociais e humanas. A Cor das Letras - UEFS, n. 14, 2013 
Nós passamos do político ao cultural e retornamos ao político em um terceiro momento ainda nesta primeira dimensão, procurando compreender como o Torém passa da esfera do lúdico folclorizado ao estatuto de objeto central das elaborações simbólicas e organizacionais da etnicidade Tremembé. Nesta parte, examinamos os trabalhos de folcloristas e as cristalizações engendradas por seus discursos a respeito do ritual Tremembé. Paradoxalmente, as reificações "saudosistas" e os exercícios de salvaguarda que Ihes acompanharam estiveram na origem mesmo de transformações políticas e simbólicas inesperadas pelos agentes. Ainda aí traçamos algumas linhas para remeter à significação das bebidas alcoólicas entre a Tremembé, quando mais uma vez os estigmas se apresentam, mas os novos sentidos também. Para finalizar esta parte de análise histórica, política e simbólica do processo de destituição e reinvenção dos Tremembé, analisamos a história recente, elaborando um quadro da diversidade interna das coletividades Tremembé que habitam o município de Itarema.

No fim, tentamos analisar o conjunto dos discursos sobre a etnicidade Tremembé, sem nenhuma pretensão de chegar a uma conclusão definitiva, apenas uma procura de sentido e uma reflexão sobre a composição heterogênea da história. Ao fazer oscilar a narrativa entre o macro político e o micro social, orientamo-nos em direção aos interstícios da cultura e da vida dessas pessoas.

Mas quem são estas pessoas? Os Tremembés não constituem uma unidade coletiva a priori, configuram conjuntos de famílias habitando várias localidades na área do município de Itarema. Estas localidades por vezes conformam coletividades relativamente homogêneas, contudo, a maior parte desta população vive dispersa e espalhada em localidades que têm como centro de convergência o distrito de Almofala. Foi em torno de Almofala que concentramos a pesquisa, sua posição axial na memória indígena a torna incontornável. Esta memória é o vetor fundamental do movimento de reconstrução da comunidade étnica, ela se associa à marginalidade histórica a qual eles estiveram relegados e revela os jogos simbólicos da composição de si. Erving Goffman (1975) e Howard Becker (1966) nos ensinaram que a marginalidade é uma construção social, cujos estigmas se integram à experiência social dos sujeitos. A partir desta posição marginal dos sujeitos e de sua produção cultural, tomamos o caminho para compreender as práticas de alcoolização.

Se, como diz Vicent Crapanzano (1991), nós impomos nosso modo dialógico como pesquisadores, é verdade também que as pessoas, os nati- 
vos, aproveitam destas ocasiões para liberar a sua própria palavra. Nossas entrevistas funcionaram como sessões de catarses relativas tanto para os atores como para nós mesmos. Para nós havia um sentido projetivo, pelas expectativas alimentadas durante a pesquisa terem se realizado em algumas ocasiões. Para eles, cremos que as entrevistas propiciaram momentos de desabafo de tensões relacionais e existenciais, como ficou explícito na discussão dos dois casos que mencionamos acima. Além de proporcionar espaços de reflexão e elaboração sobre a memória e a identidade coletiva.

0 jogo dramático é algo esperado quando consideramos o perfil dos atores em cena. Os Tremembé são bastante habituados à presença de pesquisadores desde os anos 1950, como já vimos anteriormente. Eles conhecem em parte os componentes das relações com os pesquisadores, um pacto de aliança explícito se estabelece. Aqui eu saliento minha posição de militante da causa indígena. Eu sou membro de organização não governamental com importantes ações no contexto da região Nordeste. Mas, em paralelo a esta filiação e adesão, francamente utilizada como moeda de troca nas minhas relações com eles, afirmando uma lealdade e solidariedade, há o fato da pesquisa se inscrever no registro das contradições, tensões e conflitos que atravessam a construção da identidade étnica. No lugar de contribuir para a fixação identitária, as imagens desveladas por nossas descrições, cremos, mostram a dinâmica da elaboração cultural em articulação com fontes mestiças e não puramente indígenas.

No que concerne a segunda dimensão, relativas às práticas de consumo e significados das bebidas alcoólicas, procuramos diversificar os tipos de dados coletados. 0 material etnográfico está baseado sobre observações diretas, entrevistas semi-estruturadas, registros espontâneos gravados, testemunhos durante os rituais, fotos e alguns mapas genealógicos. A descrição dos rituais ocupou uma parte considerável do trabalho, considerando que nestes espaços/tempos dramáticos se desenrolavam a própria construção do sentido coletivo relativo à identidade étnica e ao significado da bebida ritual. Descrição e interpretação se interpenetraram na escritura etnográfica ao modular nosso próprio discurso com os depoimentos, sejam de dramas de alcoolização, como no último capítulo da tese, seja em entrevistas sobre a produção da bebida e o sentido do ritual, este último aprendido pela visão do pajé da comunidade. Veremos ao final algumas das interpretações elaboradas pelo pajé a propósito do Torém e do mocororó.

É preciso registrar ainda o artifício de modular os registros do caderno de campo entre o escrito e o oral, no último caso realizando sessões de

86 Número temático: M etodologias de pesquisa em ciências sociais e humanas. A Cor das Letras 
gravação de nossas impressões cotidianas. Nós tínhamos a intenção, com esta oscilação, de reter as virtudes e os limites das duas técnicas. 0 escrito fixando pelo refletido e selecionando a própria memória na tradução das palavras bem pensadas e bem pesadas. 0 oral instigando o emocional, produzindo um fluxo narrativo que poderia ser retomado como objeto de autoanálise da construção da pesquisa e do sujeito do pesquisador. Sem qualquer pretensão de assumir uma postura inspirada na epistemologia de caráter etnopsiquiátrica, nos termos propostos por Georges Devereux (1980), nós procuramos, de qualquer maneira, acompanhar e examinar o mais próximo possível nossa própria subjetividade.

Uma atenção especial foi dada à nossa experiência participativa nas sessões de alcoolização. Estas experiências foram orientadas por um sentido de conhecimento, elas se inscrevem em uma tradição da antropologia que faz de seu exercício uma passagem para compreensão da vida e dos sentimentos coletivos. Os diálogos nos permitiram o uso de técnicas de pesquisa flexíveis. Claro que certas questões de base estruturaram as entrevistas, tais como: a percepção dos efeitos, a comparação entre as bebidas, o significado do beber no ritual e do beber em geral, a relação com a identidade étnica. Procuramos diversificar ao máximo as perspectivas: entrevistamos os líderes e os "marginais", homens e mulheres, idosos e jovens, evangélicos e adeptos da Umbanda, bebedores considerados normais e aqueles vistos e classificados como alcoólatras. 0 material fotográfico serviu como recurso etnográfico importante, dado que fixaram instantâneos estratégicos das entrevistas, dos encontros, dos espaços, das situações cotidianas e dos rituais.

0 trabalho de interpretação tomou como eixo a alcoolização e a elaboração simbólica nela implicada para a construção da identidade étnica. M ostramos como o ritual do Torém sempre esteve no centro de certa tradição lúdica de rememoração coletiva. Nesta franja cultural esquecida se refugiaram os marginais, bebendo uma bebida fermentada como a festejar a tragédia histórica que seus ancestrais viveram. Mas também neste espaço/tempo do lúdico, uma maneira de se apropriar do corpo e do espírito se instituiu, uma metáfora do paradoxo como propõe Gilles Deleuze (1969, p. 9), a afirmação de dois sentidos ao mesmo tempo. Os índios não existiam mais e, no entanto, eles realizavam um ritual indígena, diziam os folcloristas como Florival Seraine (1955). Eles eram ao mesmo tempo puro passado e puro futuro. A cultura como produto da ação social é necessariamente dinâmica. Aí ela revela outro paradoxo, o da vontade de fixar e a inelutável 
mudança imposta pelo fluxo das relações humanas. Um jogo lúdico e aparentemente ingênuo tornou-se um elemento chave desta cultura residual, onde 0 álcool parecia somente marcar ainda mais negativamente a herança estigmatizante dos índios desaparecidos. Ora, aí mesmo o discurso e a prática refundaram a memória da reconstrução de um ser coletivo, hoje sacralizando o Torém e o mocororó.

Como se não bastasse existir no plano da prática de mestiços pobres, a alcoolização do índio se cristaliza no imaginário religioso dos cultos de possessão, ou o contrário, os dois ao mesmo tempo. Exatamente neste ponto entre 0 imaginário e a prática nós colocamos a questão desta pesquisa. Qual o significado do estereótipo do índio bebedor em um contexto de reconstrução étnica, no qual um ritual de alcoolização é uma das dimensões fundantes da identidade? Que significações podem ser elaboradas em torno da bebida ritual neste contexto? E as outras bebidas alcoólicas, como são percebidas? Quais as modalidades de alcoolização dos índios e como elas são percebidas e classificadas? Enfim, trata-se sempre de compreender em que contexto as pessoas modificam a consciência e qual a significação para os sujeitos que a realizam. É preciso procurar as significações nas práticas correntes, seguindo suas temporalidades, mas sem esquecer que a experiência se funda nas referências construídas historicamente pela cultura. Esta última como teia de significação que guia a atuação social é sempre fluxo a ser interpretado no curso das interaç̧ões como nos ensina Clifford Geertz (1978, p. 15 e 27).

Entretanto, não se tratava de examinar uma unidade cultural formando um quadro homogêneo, bem mais apropriado seria pensar em um contexto atravessado por certa polifonia. Os Tremembé, como já salientamos, formam uma composição de famílias ocupando o lugar mais desfavorecido da escala social local. São agricultores e pescadores, alguns deles melhor situados, possuindo terra ou embarcações. Mas não se trata de uma cultura Tremembé única e homogênea, constituída por uma cosmologia, com um conjunto de narrativas míticas articuladas a uma organização social e política daí decorrente, estabelecendo um conjunto coerente e harmonioso.

Os Tremembé partilham um horizonte comum, composto por uma história, ou melhor, uma memória coletiva, um conjunto de crenças religiosas e mágicas e um esquema social e político que organiza as relações econômicas, políticas e familiares. Nossa etnografia examina o processo de mudança na ordem política e as tensões e conflitos que elas engendram. Se

88 Número temático: M etodologias de pesquisa em ciências sociais e humanas. A Cor das Letras 
o território é peça fundamental, enquanto móvel da disputa, as elaborações discursivas e performativas em torno do sentido da história conformam um componente decisivo. A construção etnográfica que realizamos teve a intenção de traduzir situações sociais ilustrativas da composição conflituosa e dialógica da etnicidade Tremembé em relação com a alcoolização. Ao invés de elidir nossa presença em campo como um elemento desta composição nós procuramos inscrevê-la no seio mesmo do dispositivo etnográfico.

Como nos informa Alain Eherenberg (1991, p. 5), para além de sua categorização como "flagelo social, 'as drogas', os produtos psicotrópicos (drogas ilícitas, álcool e medicamentos psicotrópicos) participam das relações com o mundo e dos climas existenciais próprios a nossas sociedades". Ele vai salientar mais adiante uma diferença, em princípio, demarcando uma fronteira de repartição cultural dos usos:

Nas sociedades não modernas, as drogas pertencem às medecinas e aos ritos
(ligadas a um tempo cíclico e aos mitos), que permitem estabelecer relações
com os deuses, com os mortos ou revelar um destino. Nas sociedades mo-
dernas, elas constituem experiências que produzem e revelam simultanea-
mente os estilos de relações que o indivíduo estabelece com ele mesmo e
com outros (EHERENBERG, 1991, p. 6).

0 álcool se inscreve no quadro das trocas sociais, meio de comunicação, "lubrificante social" como Ihe nomeia Claude Fischler (1990, p. 165). E ele é, ao mesmo tempo, um desestabilizador social e individual quando é ingerido de maneira excessiva e contínua. Em jogo está o problema fundamental do estatuto da consciência, conjugando ordem e sentido. 0 que está posto é a maneira como cada grupo humano define os limites do mundo e sua experiência de significação.

Nossa intenção foi a de fornecer um quadro etnográfico das práticas e das significações dos atos de beber, associando as definições locais dos efeitos e o lugar das bebidas nas concepções religiosas e étnicas. Ficou claro que 0 percurso que propusemos religa a história política aos meandros simbólicos, a abordagem é de uma antropologia da dinâmica cultural. Dinâmica é bem a questão, posto que os dilemas da análise são aqueles do movimento entre o tradicional e o moderno evocado por Ehrenberg, que no nosso caso assume um caráter evidente de ambiguidade. Entre os Tremembé estamos diante de uma situação cultural onde a fronteira entre 0 antigo e o novo está apagada ou ao menos bastante borrada pelo processo de reconstrução das significações culturais. As bebidas entram em registros 
variados, misturando o sagrado, o lúdico, as práticas terapêuticas, a patologização e os dilemas existenciais.

Esta situação de oscilação social e cultural vivida pelo conjunto da população local, mas que toca particularmente aqueles (os índios) que reivindicam a transformação de seus estatutos, seja como pessoas ou coletividade, parece-nos ser o nó da pesquisa. A noção de drama intervém aqui, inspirada pelos interacionistas como Erving Goffman (1975) e Howard Becker (1966), com o aporte mais recente de Victor Turner (1985), como ferramenta de clarificação do processo reflexivo engendrado por estas transformações. A reorientação do sentido se si é forjada em uma experiência culturalmente dinâmica. De uma posição marginal e folclorizada, os índios passaram a outra, não ainda consolidada, de uma coletividade específica, portadora de direitos. 0 movimento que se realiza, do desprezo social e cultural ao reconhecimento, viabiliza um conjunto de reelaborações, entre as quais a significação das relações com a bebida e a embriaguez.

Nós mostramos que os índios do Nordeste recuperam sua autoestima por uma reelaboração de crenças religiosas nas quais as plantas e as bebidas assumem um papel fundamental. Eles vão buscar inspiração no imaginário que os naturalizou como seres quase selvagens e por isto capazes de estabelecer uma comunicação com as forças da natureza. Daí a ideia de uma ciência dos índios acessível por nascimento e cujo segredo marca 0 poder de um universo cognitivo diferente daquele dos brancos.

No caso Tremembé, o que expusemos informa uma trajetória de composição de si feita de oscilações simbólicas presentes até hoje. Entretanto, esta associação potente entre o índio e a natureza orienta fortemente as elaborações culturais para dar sentido a sua história e experiência prática. A química natural que transforma um suco de fruta em bebida alcoólica serve para mostrar a continuidade com um passado e uma tradição, como se esta tivesse se originado da natureza. Esta visão foi apresentada pela entrevista do pajé Tremembé. Em certo momento, o mocororó tornase os ancestrais em uma simbiose simbólica, para todos os efeitos legítima, no âmbito do discurso de alguém encarregado de produzir interpretação para as crenças do grupo. Mas, no próprio decorrer da sua argumentação, ele percebe que as relações entre tradição e mudança são problemáticas. 0 que ele resolve invocando o mocororó como produção natural que está na base da elaboração dos novos cantos. 0 quadro construído pelo pajé encerra uma reflexão, que o diálogo com o pesquisador deslancha, através da 
qual a experiência sensorial e emotiva se traduz discursivamente, definindo um significado unitário para experimentações diversificadas.

A adoção de uma abordagem interacionista implica no nosso reconhecimento de que o consumo de drogas se inscreve em um processo simultaneamente cognitivo e emocional. Esta foi nossa proposta etnográfica no contexto das práticas de alcoolização e construção identitária entre os Tremembé, tentar compreender as bebidas e seus usos como mobilizadores e reveladores sociais e subjetivos.

\section{REFERÊNCIAS}

BALANDIER, Georges. La situation coloniale: approche théorique. Cahiers Internationaux de Sociologie, XI, p. 44-79, 1951.

BARTH, Frederik. Introduction. In: Id. Ethnic Organization of Culture Diference. Bergen Oslo, Universitets Forlaget, London, George Allen \& Unwin, 1969.

BECKER, Howard S. Outsiders: Studies in the Sociology of Deviance.London, Free Press of Glencoe, 1966.

BRUNER, Edward. Ethnography as Narrative. In: The Anthropology of Experience. Chicago: Univ. of Illinois Press 1986, p. 139-155.

CARDOSO DE OLIVEIRA, Roberto. 0 índio no mundo dos brancos. A siuação dos Tukúna do Alto Solimões. São Paulo, DIFEL, 1964.

CARDOSO DE OLIVEIRA, Roberto. Identidade, etnia e estrutura social. São Paulo, Pioneira, 1976.

CARDOSO DE OLVEIRA, Roberto. A sociologia do Brasil indígena. Brasília, Ed. da UNB, 1978.

CARDOSO DE OLIVEIRA, Roberto. A categoria de (des)ordem e a pós-modernidade da antropologia. In: CARDOSO DE OLIVEIRA, R. et al. Pós-modernidade. Campinas: Ed. UNICAMP, 1995.

CRAPANZANO, Vicent. Diálogo. Anuário Antropológico/88. Brasília, Editora Universidade de Brasília, 1991.

CUNHA, Manuela C. da. Etnicidade: da cultura residual, mas irredutível. In: Antropologia do Brasil. São Paulo, Brasiliense/EDUSP, 1986.

DELEUZE, Gilles. Logique du sens. Paris, Les Editions de M inuit, 1969.

DEVEREUX, Georges. De l'Angoisse à la methode dans les sciences du comportement. Paris, Flammarion, 1980.

EHRENBERG, Alain. Un monde de funambules. In: Id. (Dir.). Individus sous influence. Drogues, alcools, médicaments psychotropes. Série société. Paris, Éditions Esprit, 1991, p. 5-28.

FANON, Frantz. Les damnes de la Terre. Paris, M aspero, 1968.

FELDMAN-BIANCO, Bela. (Org.). Introdução. In: Id. Antropologia das sociedades contemporaneas. São Paulo, Global, 1987, p. 7-45. 
FISCHLER, Claude. Notes sur les fonctions sociales de l'alcool. In: CARO, Guy. (Org.). De l'alcoolisme au bien boire. Paris, Editions L'Harmattan,1990, p. 162-8.

GEERTZ, Clifford. A interpretacão das culturas. Rio de Janeiro, Zahar. 1978.

GLUCKMAN, Max. Análise de uma situação social na Zulululândia moderna. In: FELDM ANBIANCO, Bela. (Org.). Introdução. In: Id. Antropologia das sociedades contemporaneas. São Paulo, Global. 1987.

GOFFM AN, Erving. Stigmate, les usages sociaux des handicaps. Paris, Les Editions de Minuit, 1975.

LÉVI-STRAUSS, Claude. Antropologia estrutural dois. Rio de Janeiro, Tempo Brasileiro, 1976.

MALINOWSKI, Bronislaw. Argonautas do Pacífico Ocidental. São Paulo, Abril, 1978. Col. Os Pensadores.

M ARCUS George. Identidades passadas, presentes e emergentes: requisitos para etnografias sobre a modernidade no final do século xx ao nível mundial. Revista de Antropologia, São Paulo, USP, n. 34, p. 197-221, 1991.

MESSEDER, Marcos L. L. Etnicidade e diálogo político: a emergência dos tremembés. Dissertação M estrado. Salvador, UFBA, 1995.

MESSEDER, Marcos L. L. Rituels et drames d'alcoolisation chez les Tremembé. Lyon, Université Lumière Lyon 2, Thèse de Doctorat, 2004.

MONTERO, Paula. Reflexões sobre uma antropologia das sociedades complexas. Revista de Antropologia. São Paulo, USP, n. 34, p. 103-130, 1991.

NAHOUM-GRAPPE, V. La culture de l'ivresse. Essai de phénoménologie historique. Paris, Quai Voltaire, 1991.

NASCIMENTO, Marco Tromboni de Souza. O tronco da Jurema. Ritual e etnicidade entre os povos indígenas do nordeste: o caso Kiriri. Dissertação de Mestrado Salvador, Universidade Federal da Bahia, 1994.

OLIVEIRA, 1995. [Ver CARDOSO DE OLIVEIRA, 1995].

OLIVEIRA, João Pacheco de. Nosso governo: os Ticuna e o regime tutelar. Rio de Janeiro, Museu Nacional, 1988.

OLIVEIRA FILHO, João Pacheco de. Uma etnologia dos "índios misturados": situação colonial, territorialização e fluxos culturais. In: OLIVEIRA João Pacheco de. (Org.). A viagem da volta: etnicidade, política e reelaboração cultural no Nordeste indígena. Rio de Janeiro, Contra Capa Livraria, 1999.

OLIVEIRA JR., Gerson Augusto. Torém: brincadeira dos indios velhos. São Paulo: AnnaBlume, 1998.

SANTOS, Jocélio Teles dos. 0 dono da terra. A presença do caboclo nos candomblés da Bahia. Salvador, SarahLetras, 1995.

SERAINE, Florival. Sobre o Torém (dança de procedência indígena). Revista Trimensal do Instituto do Ceará, v. 69. Fortaleza, Ed. Instituto do Ceará, 1955.

TEDLOCK, Dennis. The Analogical Tradition and the Emergence of a Dialogical Anthropology. Journal of Anthropology Research, New Mexico, University of New Mexico, v. 35, n. 4, 1979.

92 Número temático: M etodologias de pesquisa em ciências sociais e humanas. A Cor das Letras 
TODOROV Tzvetan. Mikhail Bakhtine le principe dialogique. Paris, Éditions Du Seuil, 1981.

TURNER, Victor. On The Edge of the Bush. Anthropology as Experience. Tucson, The University of Arizona Press, 1985.

PEIRANO, Mariza. The Anthropology of Anthropology: the Brazilian Case. Brasilia, UnB. Série Antropologia, n. 110, 1991.

VALE, Carlos Guilherme 0. do. Terra, tradição e etnicidade: um estudo dos Tremembé do Ceará. Dissertação de M estrado, PPGAS/MN/UFRJ, 1993.

VAN VELSEN, Jaap. A análise situacional e o método de estudo de caso detalhado. In: FELDMAN-BIANCO, Bela. (Org.). Antropologia das sociedades contemporaneas. São Paulo, Global, 1987. 
